\title{
Contribution of geophysics for the characterization of ore deposits, case of the Bouarfa mine, Morocco.
}

\author{
Bahi Anas, Akhssas Ahmed, Ouadif Latifa, Ahmed Ait Errouhi and Kawtar Ouatiki \\ Laboratory of Applied Geophysics, Geotechnics, Engineering Geology and Environment, Mohammadia School of \\ Engineers, Mohammed V University, Rabat,Morocco
}

\begin{abstract}
Geophysical methods are one of the best ways to determine the potential of a mining area. Indeed, for the prospection of metalliferous deposits, the magnetic method remains essential as it makes it possible to characterize the extent and the depth of the anomalous bodies present in the prospected zone,mainly due to their reaction with the values of the total magnetic field. Thus, for the manganese mining zone of Bouarfa and more exactly Hammraouet, the genesis of the deposit is such that the manganese is generally associated with ferruginous minerals and clearly affect the total magnetic field. That said, the raw results obtained must imperatively be subjected to corrections to only keep the effect of the anomalous bodies on the magnetic field. Hence, we must proceed with the correction of the daytime effect then we eliminate the regional effects to get the map of the residual anomaly and finally we perform a reduction to the pole that will allow us to have well individualized and unipolar anomalies and thus allowing us to locate precisely the potentially mineralized axes. The synthesis of the various maps obtained by spatial interpolation of the data recorded in situ and corrected allows us to locate areas of mining interest and to determine the different tectonic phenomena that took place in our study area. In time, these maps will serve us to guide the subsequent mechanical surveys to confirm the results obtained by geophysical methods.
\end{abstract}

\section{Introduction}

Geophysical methods have become unavoidable for anyone interested in medium and deep geology. Even more so today for the mining geologist, since the easiest deposits to discover have already been and because we are seeking deeper and deeper depths. Thus, in the case of metalliferous deposits, the so-called geophysical methods of potential constitute the most interesting means for their characterization. As a matter of fact, the magnetic method is the most appropriate tool especially when we are dealing with a Manganese mineralization, because it is usually associated with iron. This makes it possible to measure the total magnetic field and thus calculate the effect that the presence of useful ore can have on said field. Hence, to highlight this phenomenon, we focused our interest on the mining area of Bouarfa located in eastern Morocco, north of Bouarfa, at a faulty corridor with an East-West direction.

The Manganese mine in Bouarfa has long been considered one of the largest in Morocco since 1912, reaching more than 2,000,000 tons in 1967 when the production stopped. This sudden halt could be explained by the fact that ore prices had fallen and that exploitation was becoming increasingly difficult given the means implemented at that time.
This research project proposes to lay the foundations necessary for resuming exploitation of this deposit by conducting a geophysical campaign at the formerly operated Hammraouet area. This campaign will be preceded, as usual, by a geological study of the area in question, which will take into account both the various description works carried out during the exploitation of the deposit and the observations in situ.

Therefore, first, we will describe the geological and mining context of our study area and then look into more details about the geophysical prospecting methods used and the extent of work done on the ground. Finally, a synthesis of the different results obtained will be carried out to determine the structural scheme of the mineralization in the Hammraouet mining area.

\section{I- Geological and mining context}

The Bouarfa manganese deposit is located in the province of Figuig two kilometers north of the town of Bouarfa as shown in the processed radar satellite image in Figure 1. 


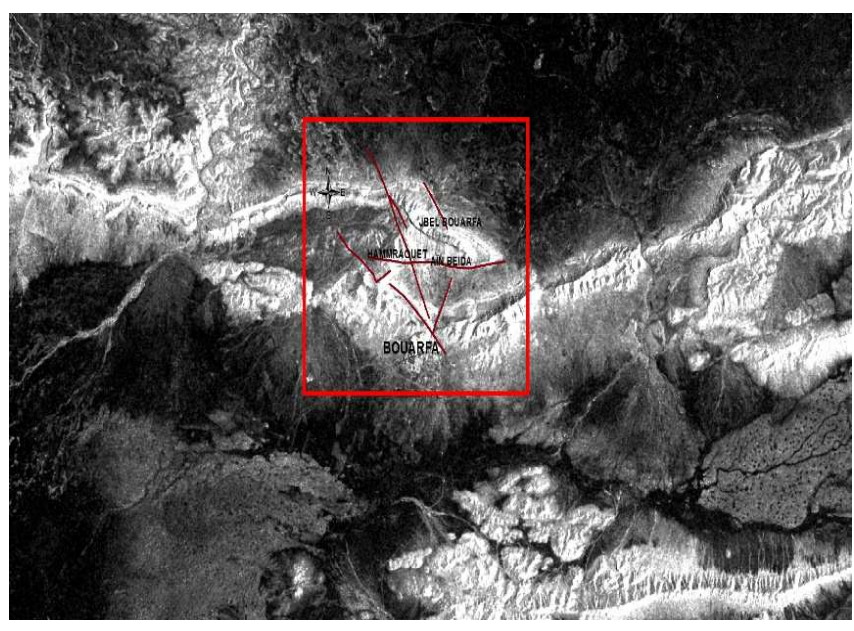

Fig.1:Radar satellite image locating the study area

The study area thus belongs to the northern border chain of the high eastern atlas, it is bordered on the north by Jbel Bou Arfa and on the south by Jbel Bou Mokhta as represented on the extract of the geological map of the region in figure 2 . It is a pleated structure dated from the Jurassic until the Cretaceous which ensures the junction between the Central High Atlas and the Saharan Atlas in Algeria. Its extensive tectono-sedimentary style in tilted blocks has generated a structure in wrinkles and depocentres.

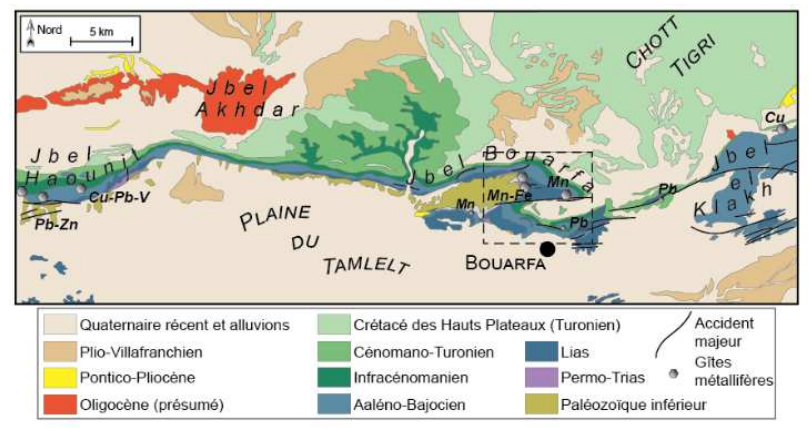

Fig.2:Geological map of Tamlelt [1]; 1/200 000, Study area is located in the frame.

The stratigraphic log shown in Figure 3 shows that the Cambro-Ordovician is confined to the Hamda formation which is outcropping to the west of our study area. It is mainly composed of quartzo-phyllades, grauwackes and some veins of siderosis.

Then there is the basic formation which is deposited in major discordance on the Cambro-Ordovician in the form of conglomerates of all kinds as well as some limestones in platelets.

The main area of interest that concerns us in terms of this unit is the buttonhole Hamda-Hammraouet. In this buttonhole, we distinguish the formation of Bou Mokhta dated lower Lias which contains three more or less distinct members as represented in figure 4.

This formation begins firstly, by the arrival of the first carbonated levels marking the liasic transgression, by a marine regime having experienced phases of emersion, then on the other hand, by a lagoon deltaic epicontinental environment, marked by evaporites deposits and by a rather pronounced phase of dolomitization. The age of the formation is attributed to the lower Lias (Hettangien Sinemurian), its power is variable from West to East and towards the South, and it varies from 50 to $150 \mathrm{~m}$ [2].

The first member of the Bou Mokhta Formation is characterized by the presence of carbonate levels in the form of small irregular brownish to black centimetric beds marking the first Liase marine transgression on the Basic Formation and characterizing the lower limit of this member. The upward sedimentation of the limb becomes more carbonated and the power of the layers becomes larger to reach decametric values. At the top of the limb is a succession of two limestone benches forming a bar of 4 to $5 \mathrm{~m}$ of power nicknamed thanks to its color "chocolate bar". This "chocolate bar" is characteristic and clearly visible in the landscape, it is the upper limit of the Member. The total power of the Lower Member is 8 to 20 $\mathrm{m}$, it can reach $50 \mathrm{~m}$ in the South-West of the study area. The lower limit of the Intermediate Member begins at the top of the "Chocolate Bar", a new sequence begins with withdrawals and returns from the sea which results in a detrital terrigenous sedimentation. Then calcareous banks are inserted, in which a lagoon environment predominates and results in a deposit of gypsum in metric lenses. Towards the summit of this limb, reddish, oolitic, bioclastic, and dolomitic limestones alternate. The power of this Member is reduced to a few meters at the northwest end, to the Southwest, it can reach $50 \mathrm{~m}$.

The upper limb "Hammraouet" finishes the formation of Bou Mokhta, it marks the landscape by its brown to blackish cliff 8 to $15 \mathrm{~m}$ high, and its lower limit begins with argillites and limestones. This member consists of two bars, the lower bar of 10 to $15 \mathrm{~m}$ of power, consisting of dolomitic limestone beds. Towards the top of this limb, the second, thinner bar settles through stratification joints in the form of reddish to brownish argillites and dolomitic limestones with biological laminae. These two bars together form the "Hammraouet Bar".

Ensuite, on retrouve la formation d'Ain Beida datée du lias inférieur moyen formée par une alternance de calcaires et d'argilites avec des minéralisations de Mn sous forme de canaux et de lentilles plus ou moins étendus.

Next, we find the Ain Beida formation dated from the lower middle lias formed by an alternation of limestones and argillites with mineralization of $\mathrm{Mn}$ in the form of channels and lenses more or less extended.

The Middle Lias happens subsequently through training Bouarfa with outcrops in the form of alternating conglomerates and shales rich in granite elements. It should also be noted that the layer of arkoses is quite important in this formation.

Finally, the slab of the high plateaus overhangs our study area in the north with a succession of dolomitic benches with bioclastic limestones and oolitic baselimestones. 


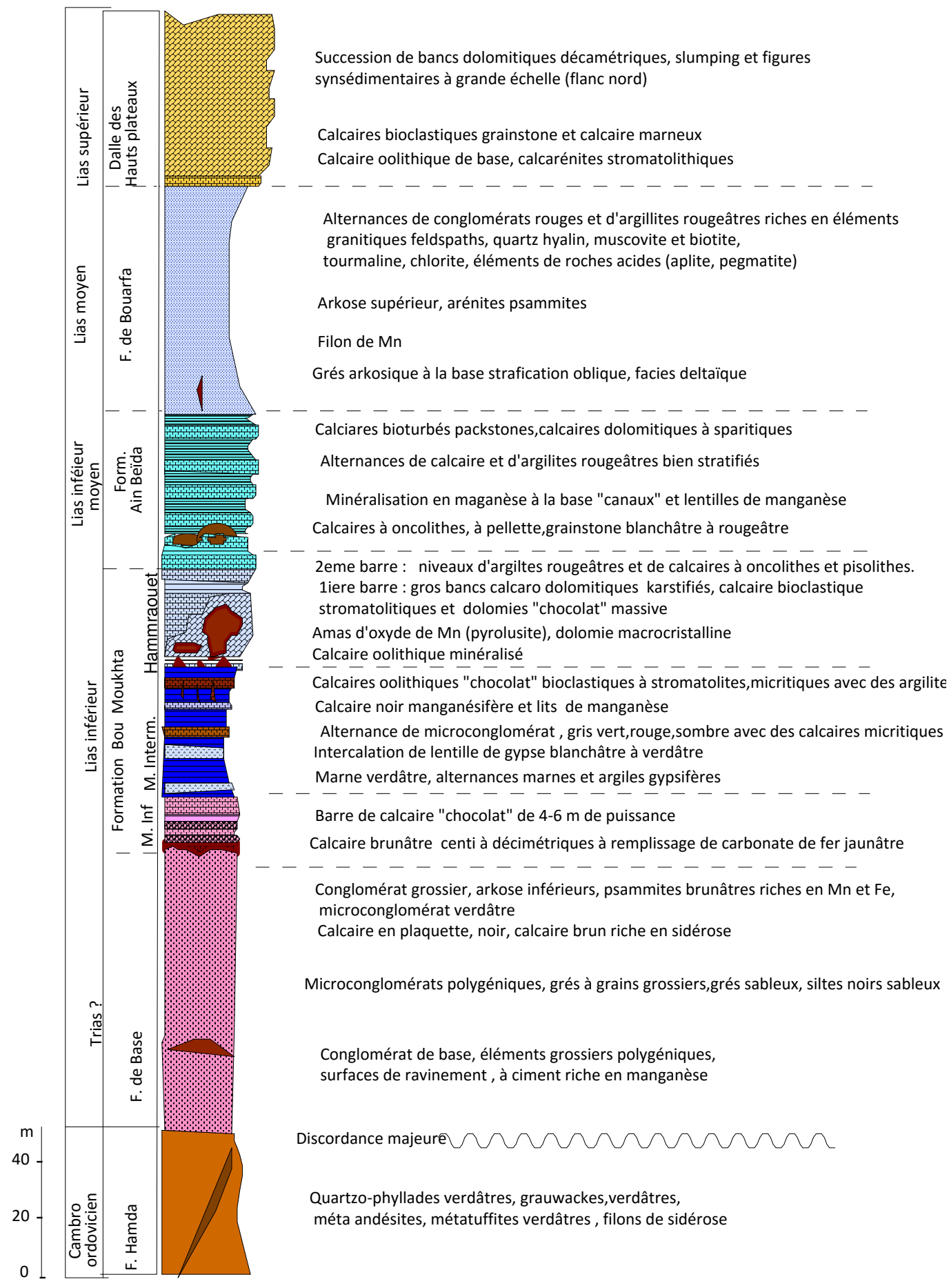

Fig 3: Stratigraphic log of the study area. 


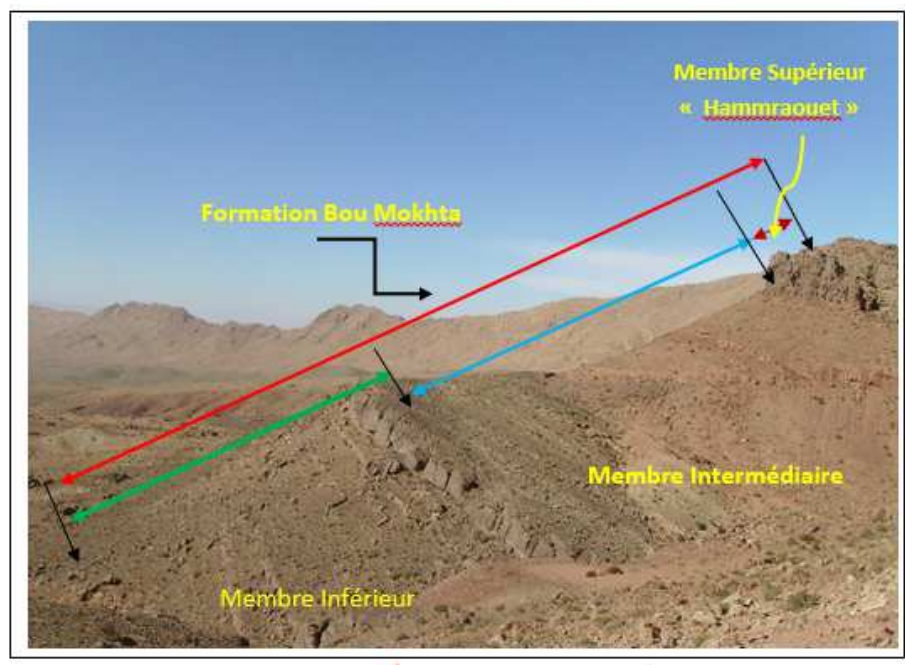

Fig.4:Schematic representation of the Bou Mokhta Formation

The mineralization at the Hammraouet zone is a substitution type in the chocolate dolomite layers and in direct relation with tectonics. Pouit and Jouravsky [2] report the presence of hausmannite, polianite (former name of pyrolusite or nsutite), pyrolusite and manganite. Several $\mathrm{Fe}$ mineralizations are also notable. The polianite is covered with a layer of goethite with inclusions of polianite. Thus at Hamaraouet, Fe is mineralogically separated from Mn [3]. This type of mineralization is the second largest in the sector after Ain Beida. It is arranged in metric heaps very rich in Mn [4-5].

Figure 5 shows the simplified structural scheme which synthetizes the geological context.

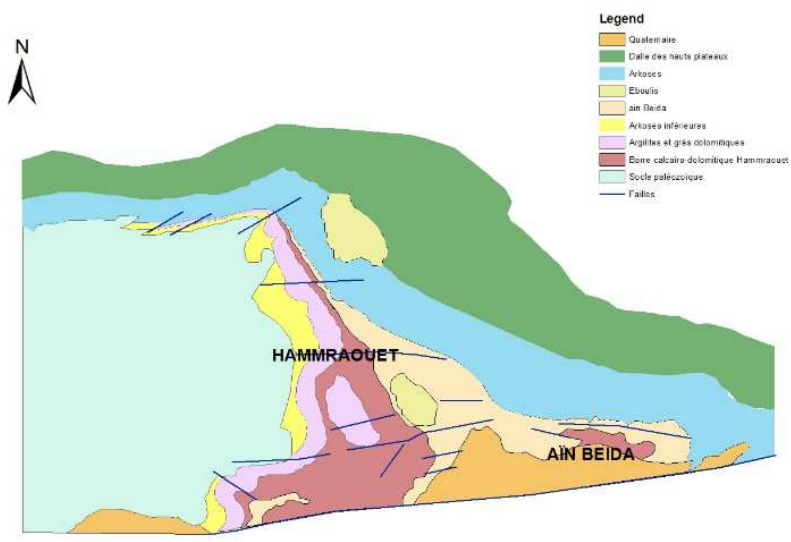

Fig.5:Simplified structural scheme of the Bouarfa Domain

\section{II- Geophysical prospecting method and work performed}

\section{Method characteristics:}

Given the nature of the mineralization and its genesis, the magnetic prospecting method has emerged as the most interesting method for recognizing the Manganese deposit at Hammraouet [6].The magnetic method is based on the measurement of the total field, which in the presence of manganese ore, in our case study, associated with iron oxides, will undergo a disturbance created by the contrast of magnetic susceptibility between the mineralization and the host [7-8].Magnetic prospecting thus consists of searching for and locating rocks, formations and deposits by anomalies or local variations that they produce in the terrestrial field [7-8].

\section{Work carried out in situ:}

The measurements carried out on our study site consisted of:

- 6 magnetic profiles spaced 25 to $50 \mathrm{~m}$ depending on the difficulties posed by the rugged terrain.

- A cumulative coverage distance of 3.48 linear $\mathrm{km}$.

- Measuring stations spaced $25 \mathrm{~m}$ apart.

The details of this work are shown in Figure 6.

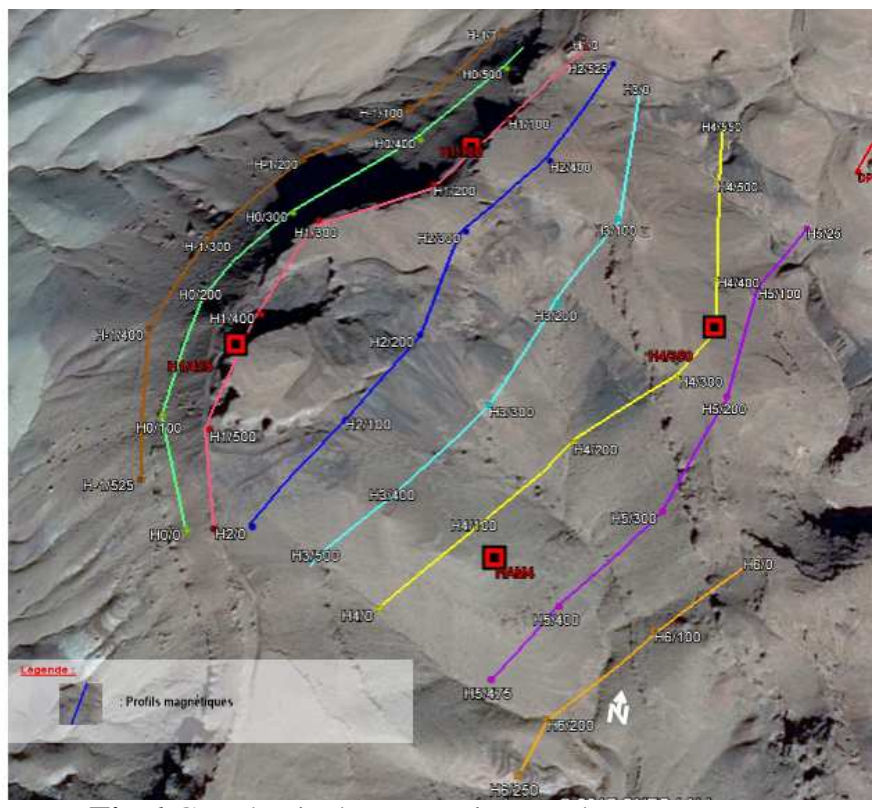

Fig.6:Geophysical prospection work map.

\section{Data correction:}

In situ data are subject to the effects of regional magnetism and other distortions that may affect the distribution of magnetic anomalies and their equilibrium. Thus, it is mandatory to correct the values of the measured magnetic field in order to obtain values representative of the magnetism of the structures in place. The first correction to be applied is due to the diurnal variations of the magnetic field, which are themselves the result of variations in the current in the ionosphere in view of the solar activity.

Then, we apply the correction of the regional field. The measured total field values are affected by regional effects. Thus, these values will be filtered so as to obtain a map of the residual magnetic field.

Once the map of the residual field obtained, the anomalies which appear there are not necessarily localized within the plumbs of the different structures and are in most cases asymmetrical and bipolar. These distortions are due to the effects of the directions of the inductive field and the magnetization, which are not always vertical. The reduction at the pole is a transformation that makes it possible to put the anomalies back in line with the structures. Its calculation requires 
knowing not only the direction of the inductive field, but also that of the magnetization which is generally that of the magnetization induced and thus parallel to the current field. [9-11]

\section{III- Results and discussions}

The results from this magnetic study lead to the production of iso-gamma maps more commonly known as the total field map (see Figure 7). This will show us the gradients of magnetic anomalies that will inform us about the probability of existence of the mineralized zones and plumbs.

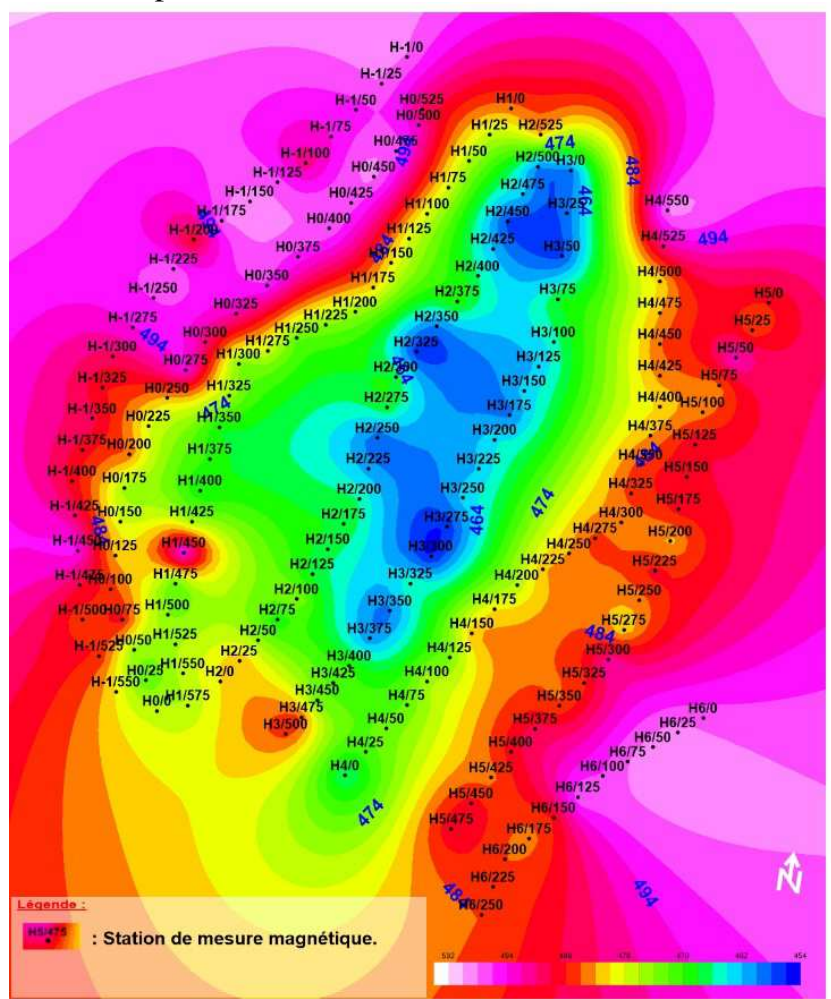

Fig.7:Total magnetic field anomalies map.

This map of the total field is the result of the graphical representation of the values of the measured total field to which the correction due to diurnal variation has been applied.

The appearance of the magnetic anomalies that appear in this map depends essentially on:

- The direction of the body relative to magnetic North.

- The magnetic susceptibility of the material forming the desired body.

- Geometry and extent.

- The depth.

- The lithology of the bedrock.

In our case, we notice the presence of a large minimum traversed by the profiles $\mathrm{H} 1, \mathrm{H} 2, \mathrm{H} 3$ and $\mathrm{H} 4$; surrounded by maxima that are located individually on the profile $\mathrm{H} 1$ and south of H3. This allows us to say that we are dealing with NW-SE oriented bipolar anomalies.

In order to eliminate the effects of the regional magnetic value on the measured gross values, which disturb the geometry of the anomalous zones and even sometimes cause false anomalies.
To do this, we subtract the values of the regional magnetic field from those of the Total field. This results in the creation of the residual magnetic map (see Figure 8 ). It represents the local magnetic effects and shows all the anomalies caused by the local existence of substances of different magnetic susceptibilities.

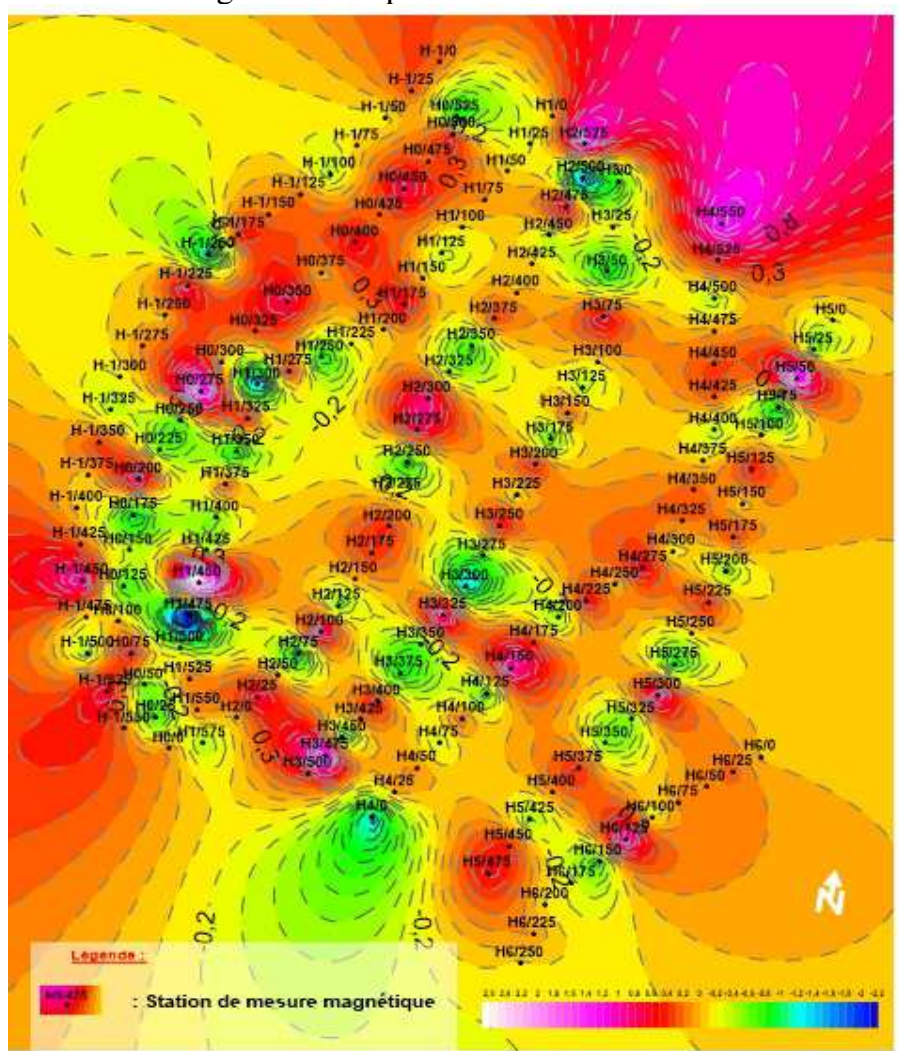

Fig.8:Residual anomalies map.

The observation of the residual map shows five alignments of bipolar anomalies intersecting perpendicularly all the 6 profiles. These alignments are parallel to the direction of the limestone bar of Hammraouaet. In the same way, each anomaly is discontinuous, which shows that we are dealing with discontinuous mineralization concentrations. To better reveal the plumb of suspected mineralized zones, we proceed to the reduction to the pole to obtain the reduced to pole magnetic map [9-11], (see Figure 9), which will allow us to have anomalies well Individualized and unipolar and thus allow us to locate with precision the potentially mineralized axes. 


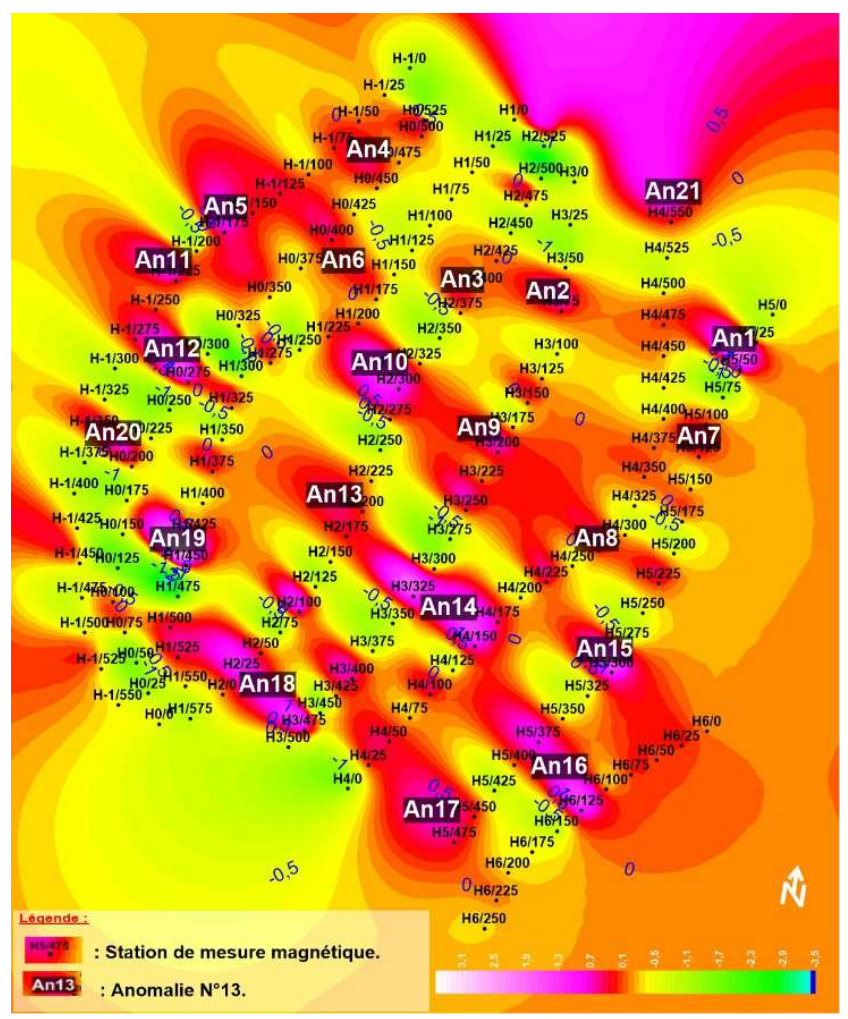

Fig.9:Reduced to the pole anomalies map

As in the residual magnetic field map, the magnetic map reduced to the pole shows a succession of discontinuous positive anomalies aligned NW-SE along five parallel axes.

The reduced to the pole magnetic map, reflects the existence of 21 generally discontinuous anomalies and distributed along NW-SE axes. These anomalies do not have the same volumes or the same gradient. The anomalies An14, An16 and An18 seem to be the most important with respect to their extensions and their magnetic gradients.

Most of these anomalies appear to consist of a single mineralized source, but perhaps due to earlier faulting effects, this source has been subdivided into several mineralized clusters. For example, the anomalies An14, An13 and An16 constitute the same cluster but it has undergone recoil forces.

The map in Figure 10 shows the probable faults that affected the potentially mineralized zones. The location of these faults will be of great importance in all direct research such as drilling and other prospecting galleries.

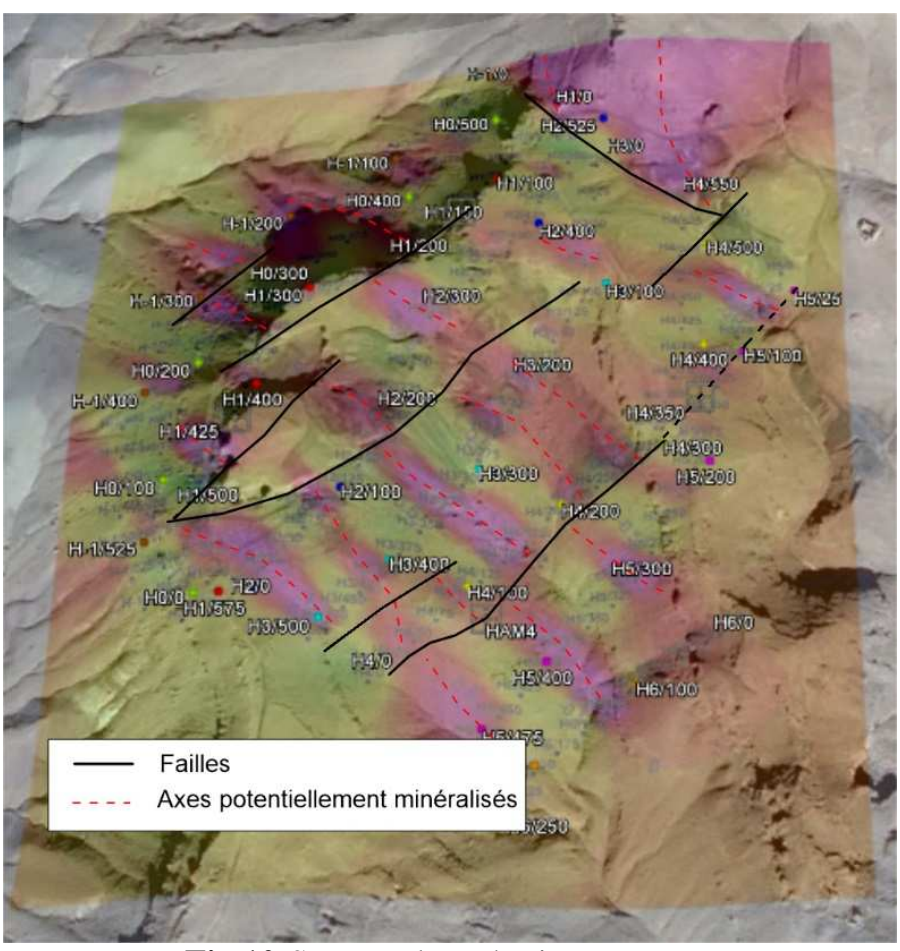

Fig.10:Structural synthesis map

\section{Conclusion}

The geophysical prospecting campaign using the magnetic method allowed us to highlight the different mineralized axes as well as the faults that affect them. This has helped us locating different areas of interest that will serve as a base to guide the mechanical survey campaigns which, in time, will give a clearer idea of the ore reserves in the study area.

That being said, magnetic study should be extended to the north and east of the initial study area to address other anomalies that may have eluded us.

In addition, the magnetic method alone cannot be sufficient to evaluate the economic potential of a deposit. Therefore, a complementary prospecting method must be used. We will be able to choose the grounding resistivity method to confirm the plumbs of the anomalies and the directions of the mineralized axes deduced from the magnetic survey.

Finally, it would be interesting to implement electrical soundings above the anomalies detected in order to have a clearer idea about the depths of the mineralized levels.

\section{References:}

1. Du Dresnay $R$ (1965) Notice géologique sur la région de Bou-Arfa. Colloque sur les gites stratiformes de plomb, zinc, et manganèse du Maroc (2 mai - 14 mai 1962). Notes et mémoires du service géologique 181:107-112.

2. Pouit G, Jouravsky G (1965) Les minéralisations manganésifères de la région de Bou-Arfa. Colloque sur les gites stratiformes de plomb, zinc, et manganèse du Maroc (2 mai - 14 mai 1962). Notes et mémoires du service géologique 181:113-131 
3. Caillère $\mathbf{S}$ (1938) Quelques observations sur la composition minéralogique et la structure des minerais de manganèse de Bouarfa. (Maroc oriental). Bull Soc Sc Nancy 2:221-250

4. Ludovic Lafforgue. Place de la minéralisation de manganèse de Bouarfa dans l'évolution mésocénozoïque de l'oriental marocain. Minéralogie. Université Paris-Saclay, 2016. Français. < NNT: 2016SACLS277 >.

5. Ludovic Lafforgue 2015. Origin of the Bouarfa Manganese Ore Deposit (Eastern High Atlas, Morocco): Insights from Petrography and Geochemistry of the Mineralization.MINERAL RESOURCES IN A SUSTAINABLE WORLD • 13th SGA Biennial Meeting 2015. Proceedings, Volume 5.

6. M. Jaffal1, Interpretation of magnetic data of the Laachach gossan (central Jebilets, Morocco): mining implications. Estudios Geológicos, 66(2) juliodiciembre 2010, 171-180

7. Debeglia N. (2005) - Estimation de la direction d'aimantation pour une réduction au pôle optimale du champ magnétique. BRGM/RP-54059-FR, 34 p., 15 fig.

8. Pierre Edouard Dousset, Jean Yves Tollardo. Etude métallogénique du val d'Aoste (Italie): essai de valorisation des ressources minières par les méthodes de prospection géophysique, géochimique ou alluvionnaire. Minéralogie. Université Scientifique et Médicale de Grenoble, 1981. Français. <tel00749389>

9. Baranov V. and Naudy H.; 1964: Numerical calculation of the formula of reduction to the magnetic pole.Geophysics, 29, 67-79.

10. Gunn P.J.; 1975: Linear transformation of gravity and magnetic fields. Geophysical prospecting, 23, 300-312.

11. G.R.J Cooper, D.R. Cowan (2005).Differential reduction to the pole. Computer and Geosciences, 31, 989-999 